\title{
Caractérisation des rhizobactéries potentiellement promotrices de la croissance végétative du maïs dans différents agrosystèmes du Sud-Bénin
}

\author{
Adolphe ADJANOHOUN ${ }^{1}$, Lamine BABA-MOUSSA ${ }^{2 *}$, Romain GLELE KAKAÏ ${ }^{3}$, \\ Marcellin ALLAGBE ${ }^{1}$, Boniface YEHOUENOU ${ }^{4}$, Henriette GOTOECHAN- \\ HODONOU $^{5}$, Rachidatou SIKIROU ${ }^{5}$, Philippe SESSOU ${ }^{4}$ et \\ Dominique C.K. SOHOUNHLOUE ${ }^{4}$
}

\footnotetext{
${ }^{1}$ Centre de Recherches Agricoles Sud/Institut National des Recherches Agricoles du Bénin. BP 03 Attogon, Benin.

${ }^{2}$ Laboratoire de Biologie et de Typage Moléculaire en Microbiologie/Département de Biochimie et de Biologie Cellulaire/Faculté des Sciences et Techniques/Université d'Abomey-Calavi/ 05 BP 1604 Cotonou, Benin.

${ }^{3}$ Faculté des Sciences Agronomiques/Université d'Abomey-Calavi. 01BP526, Abomey-Calavi, Benin.

${ }^{4}$ Laboratoire d'Etude et de Recherche en Chimie Appliquée. EPAC/ Université d'Abomey-Calavi, 01 BP 2009. Cotonou, Benin.

${ }^{5}$ Institut National des Recherches Agricoles du Bénin. BP 884 Cotonou, Benin.

*Auteur correspondant, E-mail : laminesaid@yahoo.fr, Tel ; (+229)97123468
}

\section{RESUME}

L'objectif de cette étude est de caractériser les rhizobactéries potentiellement promotrices de la croissance végétative ou encore en anglais «plant growth promoting rhizobacteria» (PGPR) vivant dans la rhizosphère de douze (12) différentes zones agroécologiques du sud-Bénin. Un échantillon composite de sol et de racines des plants de maïs est prélevé au niveau de 4 différents champs de producteurs par zone agroécologique. Des analyses agrochimiques et microbiologiques sont faites sur ces échantillons. Les résultats montrent que la flore totale des sols étudiés est riche en rhizobactéries. Quinze (15) espèces de PGPR différentes sont identifiées à de fortes concentrations dans tous les échantillons de sols et de racines. Il s'agit de trois espèces de Pseudomonas, trois espèces de Streptomyces, huit espèces de Bacillus et une espèce de Azospirillium. Les sols du sud-Bénin contiennent naturellement des rhizobactéries potentiellement promotrices de croissance végétative. Il ne se dégage pas de lien entre les propriétés chimiques des sols des différentes zones d'étude et la distribution des rhizobactéries PGPR.

(C) 2011 International Formulae Group. All rights reserved.

Mots clés : Identification, microorganisme, PGPR, sol, agroécologie.

\section{INTRODUCTION}

Le maïs (Zea mays L.) est l'une des cultures vivrières les plus pratiquées au Bénin. Il constitue l'un des aliments de base pour les populations du pays. Il se situe parmi les cultures vivrières ayant bénéficié de plus d'attention de la recherche agricole. De nombreux travaux de recherche au Bénin ont permis la mise au point de technologies de production en vue d'accroître la productivité du maïs (INRAB, 2006). D'après Loconon et Floquet (1996), très peu de ces technologies 
sont adoptées par les producteurs. Les auteurs expliquent ce fait par les changements de comportement de la part des producteurs qu'impose l'utilisation de la plupart des technologies vulgarisées.

Il convient de rechercher des technologies performantes dont l'application par les producteurs, non seulement limite les changements de leurs comportements habituels, mais également permet de créer un équilibre entre la nature et l'agriculture, un milieu où les cultures, les hommes et les autres animaux vivent, se développent et prospèrent harmonieusement. Dans cette perspective, une gestion des agro-écosystèmes intégrant l'introduction de certains microorganismes participe au développement durable en assurant une fertilité du sol à long terme (Alalaoui, 2007).

Islam et al. (2009) affirment que les rhizobactéries promotrices de croissance végétale ou PGPR, en anglais (plant growth promoting rhizobacteria), peuvent favoriser la croissance des plantes. Les auteurs suscités expliquent que la promotion de la croissance végétale par les PGPR résulte de secrétions de substances qui ont pour effets une amélioration de la nutrition des plantes colonisées par ces rhizobactéries de par la croissance racinaire, l'absorption de l'ion nitrate par la plante, la solubilisation du phosphate et la chelation du fer.

Compant et al. (2005) et Bakker et al. (2007) rapportent que les rhizobactéries PGPR contrôlent certains microorganismes pathogènes des plantes par l'induction de résistance au sein des plantes colonisées ou par la production d'antibiotiques.

Hernandez et al. (1995) affirment que l'inoculation des semences de maïs par les rhizobactéries Pseudomonas cepacia, $P$. fluorescens et Streptomyces aurantiacus, en combinaison avec une dose de $120 \mathrm{~kg} / \mathrm{ha}$ d'azote, permet d'obtenir un accroissement de plus de $25 \%$ des rendements par rapport à ceux obtenus avec la même dose d'azote mais sans inoculation par les microorganismes. Aussi, la combinaison des rhizobactéries suscitées avec une dose de $120 \mathrm{~kg} / \mathrm{ha}$ d'azote permet d'accroître de plus de $60 \%$ les rendements de maïs en comparaison avec ceux obtenus sur des parcelles sans application d'azote ni inoculation de bactéries. Shaharoona et al. (2006) affirment que même en présence de niveaux optimums d'engrais azotés, l'inoculation des semences de maïs avec Pseudomona spp contenant l'activité ACC-ésaminase améliore substantiellement la croissance et le rendement des plants.

Compant et al. (2005) indiquent que Pseudomonas cepacia produit la pyrrolnitrin qui inhibe le développement des champignons Pithium ultimum, Fusarium graminearum, Fusarium culmorum et Fusarium moniliforme qui sont des pathogènes du maïs.

Dans le cadre de la promotion de la filière maïs au Bénin, l'utilisation des rhizobactéries promotrices de la croissance végétative de cette culture est un atout majeur pour accroître la production tout en diminuant les quantités d'engrais chimiques et produits phytosanitaires à utiliser. Pour ce faire, il est nécessaire d'identifier les rhizobactéries capables de promouvoir la productivité du maïs dans chaque agrosystème des grandes zones de production de cette spéculation vivrière dans la perspective d'évaluer leurs performances en vue de leur utilisation pour améliorer les rendements de maïs.

Le présent travail vise à caractériser les rhizobactéries existant naturellement dans la rhizosphère du maïs au niveau des différents agrosystèmes en vue de leur utilisation future pour tester leurs effets réels sur la croissance vegetative du maïs.

\section{MATERIEL ET METHODES \\ Zones d'étude}

L'étude a été réalisée en 2009 dans le Sud-Bénin, dans une région comprise entre $6^{\circ} 30$ et $6^{\circ} 45$ de latitude Nord, et entre $1^{\circ} 35$ et $2^{\circ} 45$ de longitude Est (Figure 1). Cette zone regroupe les départements de l'Atlantique, de l'Ouémé, du Plateau, du Couffo, du Zou et du Mono. Elle couvre, la zone des vertisols de part et d'autre des plateaux d'Abomey et de 
Kétou; la zone des terres de barre qui connaît un crucial problème de baisse de fertilité des sols et la zone des dépressions qui présente des sols lourds et particulièrement difficiles à travailler. La zone d'étude est caractérisée par un climat subéquatorial maritime et par l'alternance de deux saisons sèches et deux saisons pluvieuses. Les précipitations moyennes annuelles augmentent de l'Ouest vers l'Est et oscillent entre $850 \mathrm{~mm}$ (Mono) et 1400 mm (Ouémé) (MAEP, 2008).

Le Tableau 1 présente les villages choisis qui sont représentatifs des différentes zones agroécologiques en étude. Les types de sol et les cultures pratiquées en 2008 y figurent également. L'association des cultures sans apport d'engrais minéraux est la pratique culturale dominante dans la zone d'étude (Soulé et al., 2008).

\section{Echantillonnage des sols}

La méthode utilisée pour l'échantillonnage des sols a consisté à fixer au hasard cinq (5) points de prélèvement sur les diagonales dans chaque champ. A l'aide d'une tarière (barre de fer en forme de « $\mathrm{T}$ » terminant par une configuration hélicoïdale ou « vis sans fin »), dix (10) échantillons ont été prélevés à $20 \mathrm{~cm}$ de profondeur et mélangés dans un seau. Cinq cent (500) grammes de ce mélange ont été prélevés et versés dans un sachet plastic stérile étiqueté. Au total, 48 échantillons de sol (à raison de 4 échantillons par village d'étude) ont été prélevés.

\section{Echantillonnage des racines des plants}

Trois (3) plants de maïs situés dans l'environnement le plus immédiat des dix (10) points de prélèvements des sols ont été arrachés. Leurs racines ont été coupées à l'aide d'un couteau et mélangées dans un seau. Trois cent (300) grammes de ce mélange ont été prélevés et versés dans un sachet plastic stérile étiqueté. Les plants de maïs prélevés étaient dans la phase de développement des grains et de maturation (entre 12 et 16 semaines après le semis). Au total, 48 échantillons de racines de maïs (à raison de 4 échantillons par village d'étude) ont été prélevés.

\section{Analyses chimiques des sols}

Les échantillons de sols prélevés ont été envoyés au laboratoire pour en déterminer les propriétés chimiques. Le pH-eau a été déterminé par la méthode électrométrique utilisant un $\mathrm{pH}$-mètre. La matière organique et le carbone ont été déterminés par la méthode de Walkley et Black (1934). Les cations échangeables ont été déterminés par la méthode de l'acétate d'ammonium décrite par Thomas (1982) et le phosphore assimilable par la méthode de Bray et Kurtz (1945).

\section{Analyses microbiologiques des sols}

Des dilutions ont été effectuées selon la méthode décrites par Speck (1976). Les quatre échantillons de chaque village ont été analysés séparément.

-Les Pseudomonas ont été recherchés sur les milieux King A et King B selon la méthode décrite par Guiraud et Galzy (1994). L'incubation a été faite à $37{ }^{\circ} \mathrm{C}$ puis à $42{ }^{\circ} \mathrm{C}$ pendant 24 à 48 heures. Les identifications ont été confirmées à l'aide de tests biochimiques (Kligler et catalase oxydase), par la microscopique et par les galeries API 20NE

-Les Streptomyces ont été étudiés selon la méthode décrite par Guiraud et Galzy (1994) et Azospirillum a été caractérisé selon la méthode décrite par Leyral et Vierling (1997) et confirmés par des tests biochimiques (Kligler et catalase oxydase), par la microscopie et par les galeries API 20NE.

-Les Bacillus ont été analysés sur le plate count agar, suivi de la recherche des enzymes respiratoires (catalases, oxydases) et des observations microscopiques. Les tests de thermo-résistance ont été aussi réalisés selon la méthode décrite par Guiraud et Galzy (1994). 


\section{Méthodes d'analyses de données}

Pour tester la différence entre les trois types de sol (terre de barre, terre de barre dégradée et vertisol) du point de vue de leurs caractéristiques chimiques et de leur microflore, les données liées à ces différentes caractéristiques ont été soumises à une analyse de la variance à un critère de classification (types de sol). Par ailleurs, afin d'identifier les caractéristiques chimiques des sols qui déterminent le plus la densité des rhizobactéries, une analyse en composantes principales (ACP) a d'abord été effectuée sur les caractéristiques chimiques des sols et les deux premières composantes principales qui sont les plus représentatives ont été extraites. Ces deux premières composantes principales ont été ensuite corrélées avec la microflore. Les caractéristiques chimiques que déterminent les axes ayant des corrélations les plus significatives avec la microflore sont alors celles qui déterminent le plus la densité en rhizobactéries dans le sol.

\section{RESULTATS \\ Propriétés chimiques des sols}

Le Tableau 2 présente les propriétés chimiques des trois types de sols recensés au cours de l'étude. On note des valeurs relativement élevées du $\mathrm{pH}_{\text {eau }}$ dans les terres de barre dégradées et les vertisols (6,5 et 6,6 respectivement). La matière organique a présenté globalement la même valeur pour les trois types de sols $(1,6 \%)$. Le phosphore assimilable a présenté la concentration la plus élevée au niveau des terres de barre non dégradées $(18,5 \mathrm{ppm})$ alors qu'il a été relativement en faible concentration dans les 2 autres types de sols $(<10 \mathrm{ppm})$. Les vertisols ont été relativement riches en $\mathrm{MgO}$ et $\mathrm{CaO}$ (4,2 et 17,4 méq/100 g de sol). Il faut aussi noter la forte variabilité du $\mathrm{CaO}, \mathrm{du} \mathrm{MgO}$, du $\mathrm{K}_{2} \mathrm{O}$ et du phosphore assimilable dans les différents types de sols considérés avec des écart-types assez élevés par rapport à la moyenne. Il n'y a pas eu de différences significatives entre les terres de barre non dégradées et les vertisols en ce qui concerne leurs caractéristiques chimiques $(\mathrm{P}>0,05)$.
Distribution des rhizobactéries dans les différentes zones agroécologiques

De manière générale, on remarque que les sols de tous les villages étudiés au sudBénin contiennent des rhizobactéries en termes de microflore totale (Tableau 2). Par contre, la densité en rhizobactéries (par gramme de sol) a été nettement plus élevée dans les vertisols $\left(81,3.10^{7} \mathrm{UFC} / \mathrm{g}\right)$ que dans les terres de barres dégradées $\left(22,2.10^{7}\right.$ $\mathrm{UFC} / \mathrm{g})$ et non dégradées $\left(12,2.10^{7} \mathrm{UFC} / \mathrm{g}\right)$ avec toutefois, une variabilité trop élevée d'une localité à une autre pour le même type de sol.

Les résultats d'analyse en composantes principales réalisée sur les propriétés chimiques des différents types de sol ont révélé que les 2 premiers axes expliquent à $74,5 \%$ la variabilité globale des caractéristiques chimiques des sols. Le premier axe a été corrélé positivement avec le

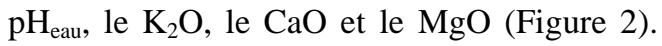
L'axe 2 a été corrélé négativement avec le $\mathrm{pH}_{\text {eau }}$ et positivement avec la matière organique et le phosphore assimilable. La corrélation entre chacun de ces deux axes et la microflore a révélé que seul l'axe 2 a été corrélé avec la microflore. De ce fait, la matière organique (MO) et le phosphore assimilable (Pass) ont favorisé la densité en microflore alors que le $\mathrm{pH}_{\text {eau }}$ a influencé négativement cette densité en microflore.

\section{Espèces de rhizobactéries PGPR présentes dans les sols}

De cette riche microflore du sol, quatre (4) genres avec quinze (15) espèces de rhizobactéries PGPR ont été identifiés. Il s'agit de : i) pour Bacillus: B. coagulans; $B$. thurigensis; B. pumilus; B. polymixa; $B$. licheniformis; B. lentus; B. circulans et $B$. firmusis; ii) pour Pseudomonas: $P$. fluorescens ; P. aeruginosa et $P$. putida; iii) pour Azospirillum: A. lipoferum et enfin iv) pour Streptomyces: $S$. hygroscopicus; $S$. rimosus et $S$. fasciculatus. 
A. ADJANOHOUN et al. / Int. J. Biol. Chem. Sci. 5(2): 433-444, 2011

Tableau 1: Villages d'étude.

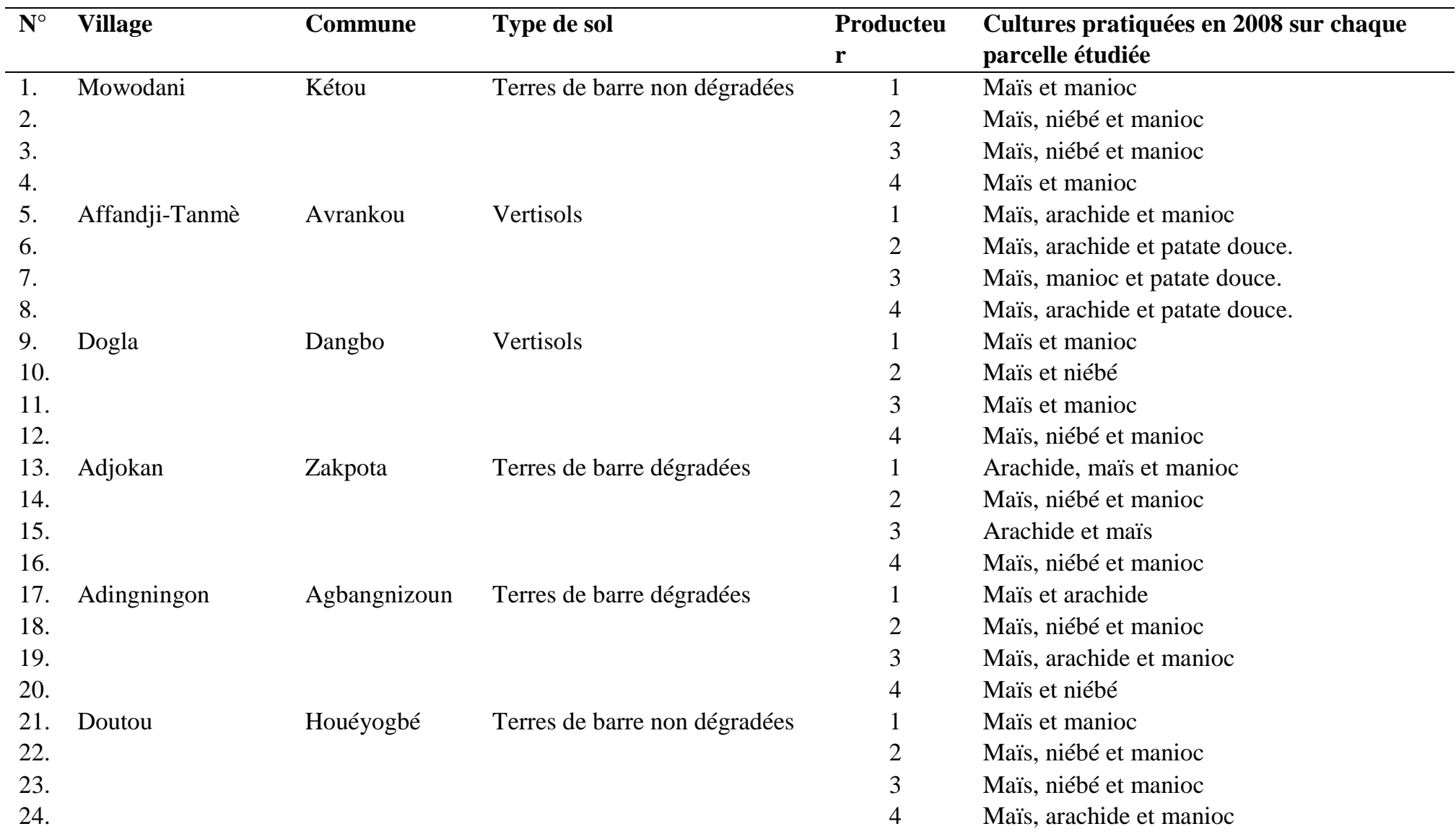


A. ADJANOHOUN et al. / Int. J. Biol. Chem. Sci. 5(2): 433-444, 2011

\begin{tabular}{|c|c|c|c|c|c|}
\hline $\mathbf{N}^{\circ}$ & Village & Commune & Type de sol & $\begin{array}{l}\text { Producteu } \\
\mathbf{r}\end{array}$ & $\begin{array}{l}\text { Cultures pratiquées en } 2008 \text { sur chaque } \\
\text { parcelle étudiée }\end{array}$ \\
\hline 25. & Tchi-Ahomadégbé & Lalo & Vertisols & 1 & Maïs et niébé \\
\hline 26. & & & & 2 & Maïs et manioc \\
\hline 27. & & & & 3 & Maïs, niébé et manioc \\
\hline 28. & & & & 4 & Maïs, niébé et manioc \\
\hline 29. & Lagbavé & Aplahoué & Vertisols & 1 & Maïs, niébé et manioc \\
\hline 30. & & & & 2 & Maïs et coton \\
\hline 31. & & & & 3 & Maïs et coton \\
\hline 32. & & & & 4 & Maïs, niébé et manioc \\
\hline 33. & Agbodji & Bopa & Terres de barre non dégradées & 1 & Maïs et manioc \\
\hline 34. & & & & 2 & Maïs et niébé \\
\hline 35. & & & & 3 & Maïs et manioc \\
\hline 36. & & & & 4 & Maïs, arachide et manioc \\
\hline 37. & Hayakpa & Tori & Vertisols & 1 & Maïs, niébé et manioc \\
\hline 38. & & & & 2 & Maïs, niébé et manioc \\
\hline 39. & & & & 3 & Maïs, arachide et manioc \\
\hline 40. & & & & 4 & Maïs, niébé et manioc \\
\hline 41. & Niaouli & Allada & Terres de barre non dégradées & 1 & Maïs et manioc \\
\hline 42. & & & & 2 & Maïs et manioc \\
\hline 43. & & & & 3 & Maïs et niébé \\
\hline 44. & & & & 4 & Maïs \\
\hline 45. & Colli Bossouvi & Toffo & Vertisols & 1 & Maïs et manioc \\
\hline 46. & & & & 2 & Maïs, arachide et manioc \\
\hline 47. & & & & 3 & Maïs, arachide et manioc \\
\hline 48. & & & & 4 & Maïs et manioc \\
\hline
\end{tabular}


A. ADJANOHOUN et al. / Int. J. Biol. Chem. Sci. 5(2): 433-444, 2011

Tableau 2: Caractéristiques chimiques et densité en microflore des différents sols.

\begin{tabular}{|c|c|c|c|c|c|c|c|}
\hline \multirow{2}{*}{ Caractéristiques chimiques } & \multicolumn{2}{|c|}{ Terre de barre } & \multicolumn{2}{|c|}{ Terre de barre dégradée } & \multicolumn{2}{|c|}{ Vertisol } & \multirow{2}{*}{ Prob. } \\
\hline & $\mathrm{m}$ & $\mathrm{s}$ & $\mathrm{m}$ & $\mathrm{s}$ & $\mathrm{m}$ & $\mathrm{s}$ & \\
\hline $\mathrm{pH}-\mathrm{H}_{2} \mathrm{O}$ & 6,2 & 0,9 & 6,5 & 1,6 & 6,6 & 0,7 & 0,823 \\
\hline $\mathrm{MO}(\%)$ & 1,6 & 0,2 & 1,6 & 0,8 & 1,7 & 0,2 & 0,766 \\
\hline Pass (Ppm) & 18,5 & 15,3 & 4,0 & 2,8 & 9,2 & 7,4 & 0,275 \\
\hline $\mathrm{K}_{2} \mathrm{O}$ (méq/100 g) & 0,2 & 0,2 & 0,0 & 0,0 & 0,2 & 0,2 & 0,478 \\
\hline $\mathrm{CaO}$ (méq/100 g) & 4,7 & 3,4 & 1,3 & 0,4 & 11,7 & 17,4 & 0,554 \\
\hline MgO (méq/100 g) & 1,7 & 0,9 & 0,6 & 0,3 & 3,1 & 4,2 & 0,595 \\
\hline Microflore (x10 $\left.{ }^{7}\right)$ & 12,2 & 1,8 & 22,2 & 24,7 & 81,3 & 166,8 & 0,670 \\
\hline
\end{tabular}




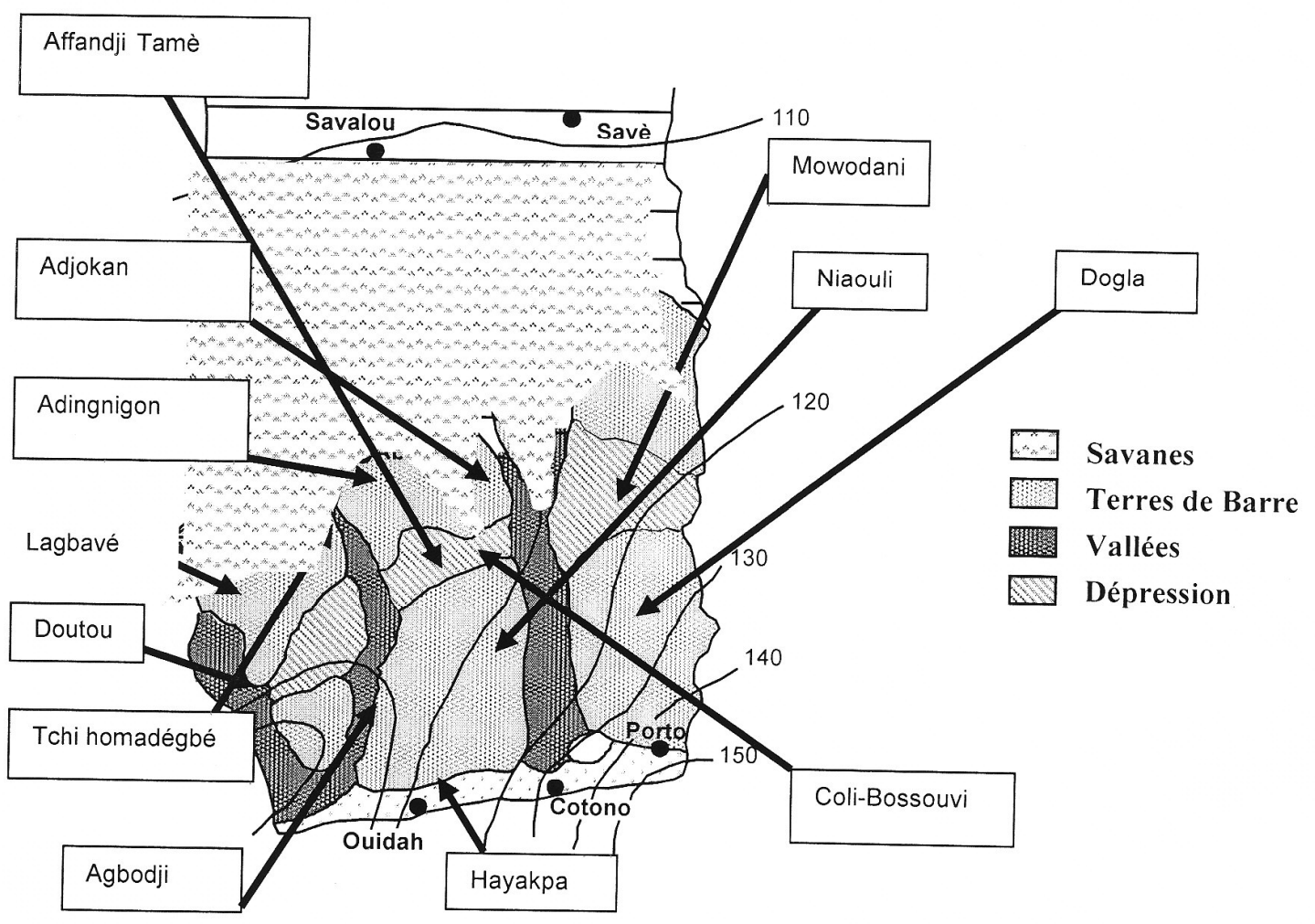

Figure 1 : Milieu d'étude et sites de prélèvement d'échantillons de sol et de racines de plants de maïs. 
A. ADJANOHOUN et al. / Int. J. Biol. Chem. Sci. 5(2): 433-444, 2011

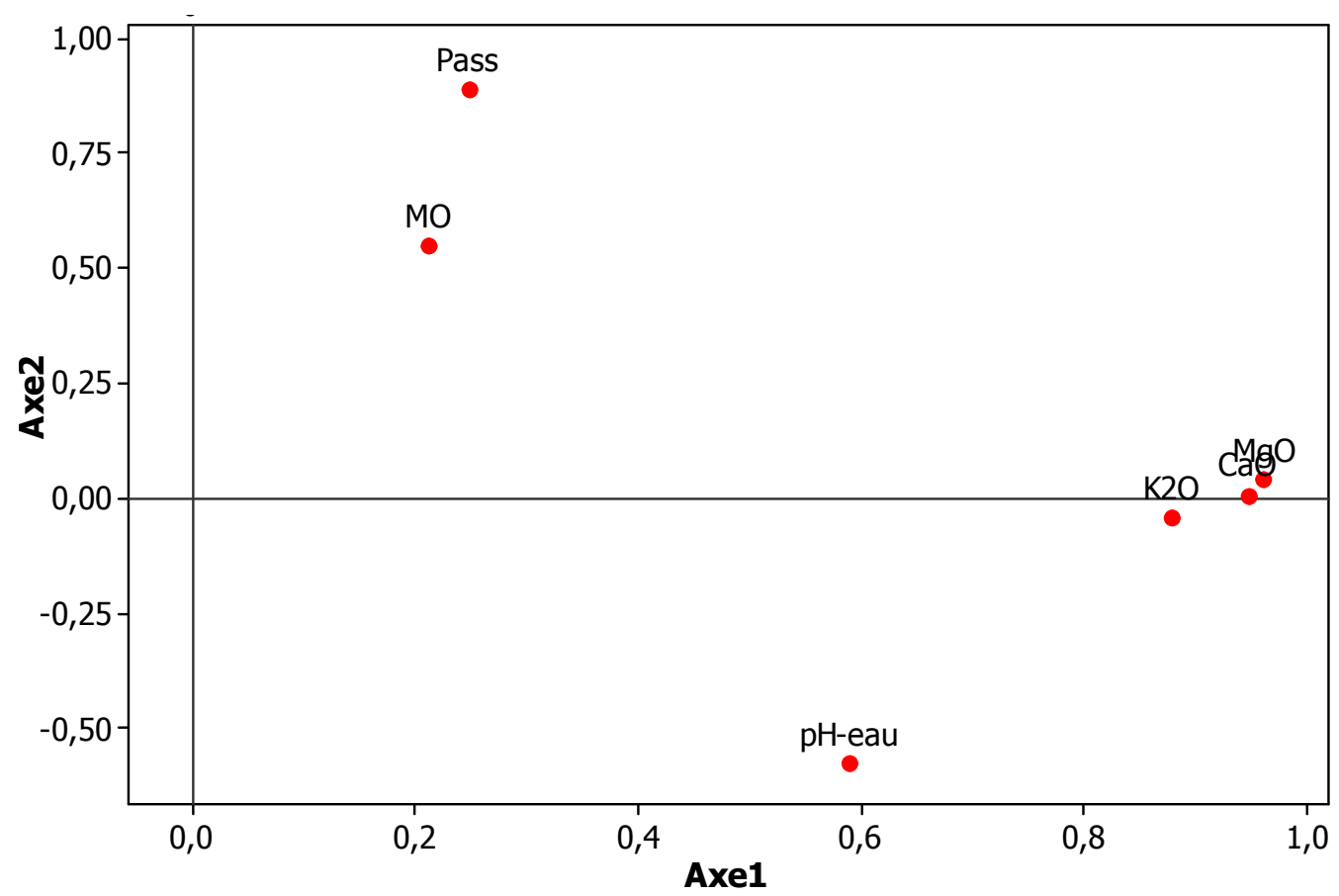

Figure 2 : Projection des caractéristiques chimiques dans le système d'axes défini par les composantes principales. 


\section{DISCUSSION}

Les valeurs relativement élevées de la somme des bases et de la capacité d'échange cationique des vertisols et des terres de barre non dégradées peuvent s'expliquer par le fait que ces types de sol sont majoritairement situés dans les vallées. Ce sont des sols originellement riches. Toutefois et à l'instar des sols très dégradés, le potassium, avec une valeur de $\mathrm{K}_{2} \mathrm{O}$ de 0,2 méq/100g de sol, y est globalement déficitaire par rapport au calcium $(\mathrm{Ca} / \mathrm{K}=84,15)$ et au magnésium $(\mathrm{Mg} / \mathrm{K}=$ 21,51). De même, on note des déséquilibres entre le calcium, le magnésium et le potassium. Ces résultats sont en conformité avec ceux rapportés par Adjanohoun (2006). Malgré ces valeurs élevées de la somme des bases et de la capacité d'échange cationique des vertisols et des terres de barre non dégradées, il est nécessaire d'apporter des nutriments au sol car les quantités de nutriments que contiennent ces sols sont insuffisantes pour satisfaire les besoins du maïs (Yallou et al., 2010). Les rendements de 4 à 6 t/ha de maïs sont obtenus avec l'application de $120 \mathrm{~kg}$ de N, $60 \mathrm{~kg}$ de $\mathrm{P}_{2} \mathrm{O}_{5}$ et $60 \mathrm{~kg}$ de $\mathrm{K}_{2} \mathrm{O}$ dans ces vertisols et terres de barre non dégradées (Yallou et al., 2010). Dans cet ordre d'idée, Diels et al. (2003) rapportent qu'un hectare de maïs produisant 2,5 tonnes de grain extrait en moyenne $175 \mathrm{~kg}$ de $\mathrm{N}, 90 \mathrm{~kg}$ de $\mathrm{P}_{2} \mathrm{O}_{5}, 100 \mathrm{~kg}$ de $\mathrm{K}_{2} \mathrm{O}, 15 \mathrm{~kg}$ de $\mathrm{CaO}, 15 \mathrm{~kg}$ de $\mathrm{MgO}$ et $10 \mathrm{~kg}$ de $\mathrm{S}$.

Les résultats des analyses microbiologiques (Tableau 2) prouvent que l'écosystème du sol du sud-Bénin est viable. Reau et Gigandon (2000) rapportent que la microflore du sol, par sa diversité et son activité, est sans doute le maillon central de l'écosystème des sols. Les concentrations de rhizobactéries PGPR enregistrées dans les sols $\mathrm{du}$ sud-Bénin indiquent très bien que l'utilisation de ces rhizobactéries pour promouvoir la croissance végétative est possible. Ahmad et al. (2006) ont mis l'accent sur la colonisation des racines des plants par les rhizobactéries du fait de l'inoculation des semences.

Shaharoona et al. (2006) mentionnent de façon particulière l'efficacité de Pseudomonas spp avec un accroissement significatif des rendements du maïs lorsque les plantes de maïs reçoivent des quantités adéquates d'azote. Kang et al. (2010) rapportent l'action positive de Bacillus spp, Pseudomonas spp et Azospirillum sur la croissance et le rendement du blé et du maïs.

La corrélation entre la microflore et les propriétés chimiques est positive et significative. En effet, un pH-eau élevé affecte négativement la densité en microflore du sol. Par contre, une valeur élevée de la matière organique et $\mathrm{du}$ phosphore assimilable font augmenter la densité en microflore des sols (Prob.= 0,603) (Figure 2).

\section{Conclusion}

Les sols du sud-Bénin contiennent naturellement des rhizobactéries potentiellement promotrices de croissance végétative. Quinze (15) espèces de PGPR (3 espèces de Pseudomonas, 3 espèces de Streptomyces, 8 espèces de Bacillus et Azospirillium lipoferum) sont identifiées à de fortes concentrations. Il est judicieux de mettre au point des technologies permettant aux producteurs d'utiliser ces rhizobactéries pour accroître les rendements de maïs au niveau des différents agrosystèmes avec des réductions des quantités d'engrais minéraux et de pesticides chimiques. Les résultats obtenus contribuent à l'établissement d'un équilibre entre la nature et l'agriculture.

\section{REMERCIEMENTS}

Les auteurs remercient l'Institut National des Recherches Agricoles du Bénin (INRAB) pour avoir financé ces travaux.

\section{REFERENCES}

Adjanohoun A. 2006. Nutrition du manioc sous différentes combinaisons de NPK au 
Sud du Bénin. Bull. Rech. Agro. Benin, (52): 1-6.

Ahmad F, Ahmad I, Khan MS. 2006. Screening of free-living rhizospheric bacteria for their multiple plant growth promoting activities. Microbiol. Res., 163(2): 173-181.

Alalaoui AC. 2007. Fertilisation minérale des cultures : les éléments fertilisants majeurs (Azote, Potassium et Phosphore). Bulletin Mensuel d'Information et de Liaison, (155): 1-4.

Bakker PAHM, Raajnakers JM, Bloemberg GV, Höfe M, Lemanceau P, Cooke M. 2007. New perspectives and approaches in plant growth-promoting rhizobacteria research. Euro. J. Plant Pathol., 119(3): 241-242.

Bray RH, Kurtz LT, 1945. Determination of total, organic and available forms of phosphorus in soils. Soil Science, 59(1): $39-45$

Compant S, Duffy B, Nowak J, Clément C, Barka EA. 2005. Use of plant growthpromoting bacteria for biocontrol of plant diseases: Principles, mechanisms of action and future prospects. Appl. Environ. Microb., 71(9): 4951-4959.

Diels JK, Aïhou E, Iwuafe R, Merckx B, Vanlauwe. 2003. Evaluer les options pour le maintien du taux de carbone organique dans le sol en agriculture intensive en savane d'Afrique de l'Ouest à l'aide du modèle Rothamsted Carbone. In Outils d'Aide à la Décision pour l'Agriculture en Afrique Subsaharienne, Struif Bontkes TE, Wopereis MCS (Eds). 151-161.

Guiraud J, Galzy P. 1994. Contrôle Microbiologique dans les Industries Agroalimentaires (2 $\left.2^{\mathrm{ème}} \mathrm{eds}\right)$. Doin.

Hernandez AN, Hernandez A, Heydrich M, 1995. Seleccion de rhizobacterias asiciadas al cultivo del maiz. Cultivos Tropicales, 16(3): 5-8.

INRAB, 2006. Contribution de la Recherche à la Promotion des Filières Agricoles

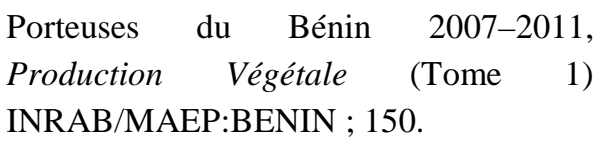

Islam MR, Madhaiyan M, Deka Boruah HP, Yim W, Lee G, Saravanan VS, Fu Q, Hu H, Sa T. 2009. Characterization of plant growth-promoting traits of three-living diazotrophic bacteria and their inoculation effects on growth and nitrogen uptake of crop plants. $J$. Microbiol. Biotechnol., 19(10): 12131222.

Kang Y, Cheng J, Mei L, Yin S. 2010. Screening and identification of plant growth-promoting rhizobacteria. Wei Sheng Wu Xue Bao., 50(7): 853-861.

Leyral G, Vierling E. 1997. Microbiologie et toxicologie des aliments, Biosciences et techniques, Centre régional de documentation pédagogique d'Aquitaine, deuxième édition.

Loconon D, Floquet A. 1996. Etude des processus de l'adoption dans le cadre d'un programme de recherche pour le développement d'innovations agroforestières et de maintien de la fertilité au BasBénin. Enquête en début du processus (fin d'année 1). Rapport $\mathrm{n}^{\circ}$ 7. Cotonou, SFB 308, projet G5, p.32.

MAEP. 2008. Étude Diagnostic et Analyse Institutionnelle pour la Promotion des Filières Agricole. P.7.

Reau R, Gigandon C. 2000. Les indicateurs de pertes d'azote en systèmes de culture colza-céréale : cas du solde azote apportexport. Les Rencontres annuelles du Cetiom. Colza 18-23.

Shaharoona AAZ, Muhammad Arshazachir B, Azeem Kalid A. 2006. Performance of Pseudomonas spp. containing ACCdeaminase for improving growth and yield of maize (Zea mays L.) in the presence of nitrogenous fertilizer. Soil Biology and Biochemistry., 38(9): 29712975. 
Soulé BG, Yérima B, Soglo A, Vidégla E. 2008. Rapport diagnostic du secteur agricole du Bénin : Synthèse réalisée dans le cadre de la formulation du PNIA. ECOWAP/PDDAA. Août 2008. 124 p.

Speck ML. 1976. Compedium of Methods for Examination of Food Microbiological. American Pub Health Assoc: Washington DC; 417-423.

Thomas GW. 1982. Exchangeable cations. In : Methods of Soil Analysis. Agronomy, 9: 154-157.

Walkley A, Black CA. 1934. An examination of the degtjareff method for determining soil organic matter and a proposal modification of the chromic acid titration method. Soil Sci., 37(1): 29-38.

Yallou CG, Aïhou K, Adjanohoun A, Baco M N, Sanni OA, Amadou L. 2010. Répertoire des Variétés de Maïs Vulgarisées au Bénin. Document Technique d'Information et de Vulgarisation. Dépôt légal $\mathrm{N}^{\circ} 4920 \mathrm{du}$ 03/12/2010, du 4ème trimestre, Bibliothèque Nationale (BN) du Bénin. ISBN : 978-99919-368-3-3-4, 19 p. 